\title{
Retraction Note: Research on urban modern architectural art based on artificial intelligence and GIS image recognition system
}

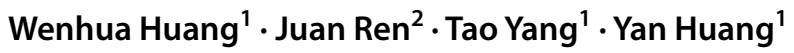

Published online: 2 December 2021

C) Saudi Society for Geosciences 2021

Retraction Note: Arabian Journal of Geosciences (2021) 14: 895 https://doi.org/10.1007/s12517-021-07222-z

The Editor-in-Chief and the Publisher have retracted this article because the content of this article is nonsensical. The peer review process was not carried out in accordance with the Publisher's peer review policy. The authors have not responded to correspondence regarding this retraction.

The original article can be found online at https://doi.org/10.1007/ s12517-021-07222-z.

Juan Ren

renjuan67268@sina.com

1 School of Civil Engineering and Architecture, Shaanxi University of Technology, Hanzhong 723001, China

2 Collaborative Innovation Center of Biological Resources in Qinba Mountains, Shaanxi University of Technology, No.1 Dongyihuan Road, Hanzhong 723001, Shaanxi, China 